\title{
Atwater Leads Executive Committee in 2000
}

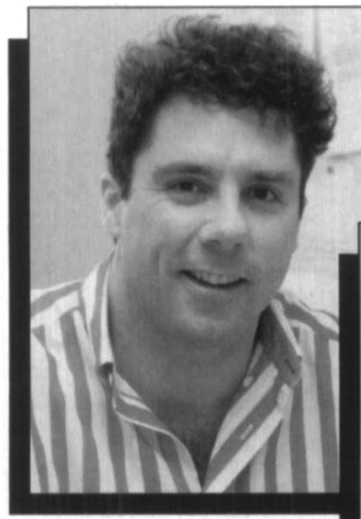

Harry A. Atwater
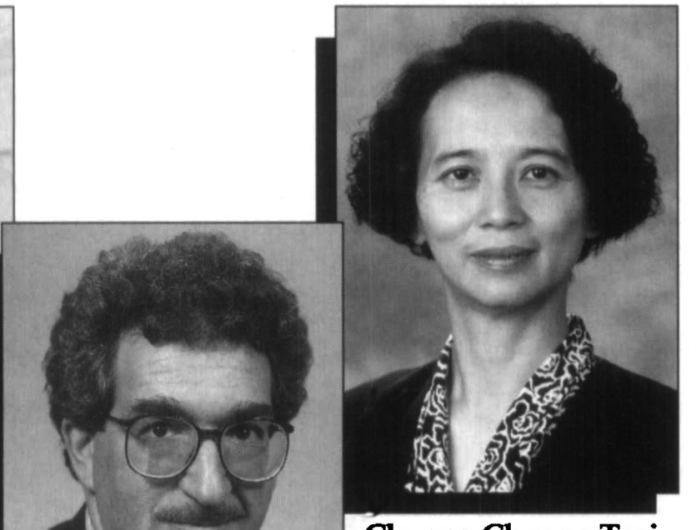

Chuang Chuang Tsai

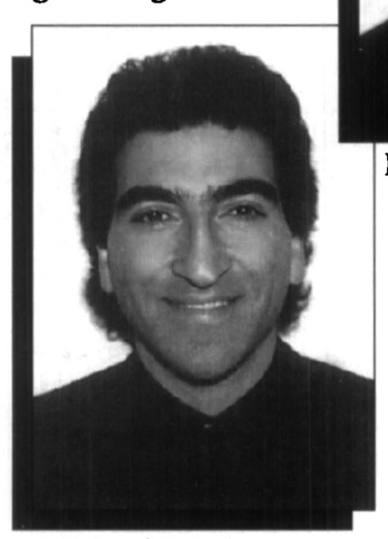

Michael J. Aziz

tional Laboratory; Caroline A. Ross, Massachusetts Institute of Technology; Alan I. Taub, Ford Motor Company; and Rudolf M. Tromp, IBM T.J. Watson Research Center. Merrilea J. Mayo (Pennsylvania State University) remains as Treasurer, serving the second year of her term. The Council has re-elected Michael J. Aziz (Harvard University) and Alexander $\mathbf{H}$. King (Purdue University) as two Councillors to serve one-year terms on the Executive Committee.

The newly elected MRS Councillors are Orlando Auciello, Argonne National Laboratory; Anne M. Mayes, Massachusetts Institute of Technology; and $\mathbf{R}$. Stanley Williams, Hewlett-Packard Laboratories. They will serve three-year terms beginning January 1, 2000, and join the following current members of Council: Michael J. Aziz; Katayun (Katy) Barmak, Carnegie Mellon University; John W. Cahn, National Institute of Standards and Technology; Anthony K. Cheetham, University of California-Santa Barbara; David J. Eaglesham, Bell Laboratories, Lucent Technologies; A. Lindsay Greer, Cambridge University; Alexander $\mathbf{H}$. King; Karen Maex, IMEC, Belgium; Stephen J. Pennycook, Oak Ridge Na-

\section{Harry A. Atwater \\ President}

Harry A. Atwater is associate professor of applied physics at the California Institute of Technology. He focuses his research on the synthesis and characterization of new thin-film electronic and photonic materials, and the development of new analytic and processing methods for electronic materials. He has active interests in ion-surface interactions, epitaxial growth of semiconductors, and semiconductor nanocrystals, as well as in situ analytic tools for thin-film growth such as reflection electron energy loss spectroscopy.

Prior to joining Caltech as assistant professor in 1988, Atwater received a PhD degree in electrical engineering from the Massachusetts Institute of Technology in 1987. He was an IBM Postdoctoral Fellow in applied physics at Harvard University (1987-1988), and he received an NSF Presidential Young Investigator Award in 1989. For 15 years, Atwater has been an active contributor to Spring and Fall MRS Meetings. He co-organized four MRS technical symposia, co-chaired the 1997 MRS Fall Meeting, and has served as chair of the MRS Graduate Student Awards Subcommittee and as MRS Councillor and Vice President/President-Elect. He is the first MRS Graduate Student Award recipient (1985) to serve as MRS president.

\section{Martin L. Green}

Vice President

(President-Elect)

Martin L. Green is a Member of Technical Staff in the Silicon Electronics Research Laboratory at Bell Laboratories/Lucent Technologies (Murray Hill, NJ). For the past five years he has focused his research on the growth and characterization of ultrathin dielectric films for silicon microelectronics applications. His other research interests have included rapid thermal processing, chemical vapor deposition, semiconductor heterostructures, martensitic phase transformations, plasticity of ordered alloys and ionic crystals, magnetic materials and powder metallurgy.

After receiving his BS (1970) and MS (1972) degrees in metallurgy from the Polytechnic Institute of Brooklyn, Green 
received his $\mathrm{PhD}$ degree (1978) in materials science from the Massachusetts Institute of Technology. He is author or co-author of over 100 refereed papers and has edited several books. He also holds 12 patents.

During his involvement with MRS since 1976, Green has co-organized four symposia, served as a Meeting Chair for the 1993 Spring Meeting, chaired the MRS Bulletin Book Review Board, and served as councillor (1995-1998), during which time he nurtured the concept of MRS Topical Workshops. The first two MRS workshops ran last summer.

\section{Chuang Chuang Tsai \\ Secretary}

Chuang-Chuang Tsai is Senior Director of Strategic Marketing and Technology at $\mathrm{AKT}$, an Applied Materials company (Santa Clara), an equipment manufacturer for the flat-panel display industry. Prior to joining AKT in 1997, she was a technical program manager at dpiX, a spin-off from Xerox Palo Alto Research Center, developing flat-panel display and medical-imaging technology, and, from 1978 to 1996, she worked at Xerox-PARC. Her research interests include materials, process, and devices of amorphous, microcrystalline, and polycrystalline silicon; plasma-enhanced chemical vapor deposition; laser crystallization; hydrogen effect on film growth and defect passivation; thin-film transistors and diodes; metal/silicon interfaces; and optical recording. Her current focus is on active-matrix liquid-crystal display and medical-imaging technology.

Tsai received her $\mathrm{PhD}$ degree from the University of Chicago in 1978. She was a recipient of the Xerox Corporate Research Group (CRG) Excellence in Science and Technology Award in 1989 and 1993. She is co-holder of U.S. patents, a co-author of over 100 scientific papers, and co-editor of six symposium proceedings on the topics of microcrystalline and nanocrystalline semiconductors, and integrated-circuit and solid-state technology.

Tsai is serving her second term as MRS Secretary. She has co-organized three MRS symposia, and has served on the Meetings Quality Subcommittee, the Program Development Subcommittee, the Program Committee, and the editorial board of $M R S$ Bulletin. She co-chaired the 1996 MRS Spring Meeting.

\section{Merrilea J. Mayo \\ Treasurer}

Merrilea J. Mayo is an associate professor of materials science and engineering at the Pennsylvania State University. Her research interests are in the areas of processing and properties of nanocrystalline ceramics and of superplasticity. She received her $\mathrm{PhD}$ degree in materials science and engineering from Stanford University in 1988.

Mayo has received a Fellowship from the Japan Society for the Promotion of Science (1993) and from the Exxon Foundation (1982-1984) and the NSF Presidential Young Investigator Award (19911996). She has served on the National Research Council's Advisory Panel on the National Institute of Standards and Technology (NIST) and on the Advisory Committee on Army After Next (AAN) Logistics. She has over 70 authored and co-authored publications.

Within MRS, Mayo has served on the External Affairs and Public Affairs Committees since 1994 and has previously served on the Graduate Student Award Subcommittee, Program Planning Committee, Long-Range Planning Committee; on Council; and as chair and symposium organizer. She was part of the MRS Headquarters Building Task Force and is involved in developing MRS's materials-related interactive displays known as Materials MicroWorld. She has recently completed her tenure as the Materials Research Society/ Optical Society of America (1998-1999) Congressional Science and Engineering Fellow

\section{Ronald Gibala \\ Immediate Past President}

Ronald Gibala is the Frances E. Van Vlack Professor and former chair of the Department of Materials Science and Engineering at the University of Michigan. His current research interests are in the area of mechanical behavior of materials, with recent emphasis on intermetallic alloys and related quasi-brittle materials.

After receiving his BS degree in metallurgical engineering from Carnegie Mellon University (1960) and his MS (1962) and PhD (1964) degrees in metallurgical engineering from the University of Illinois at Urbana-Champaign, Gibala taught at Case Western Reserve University from 1964 to 1984 and was associate director and director of the CWRU Materials Research Laboratory during the latter part of that time. He joined the University of Michigan in 1984.

Gibala has served on numerous advisory committees and participated in various professional societies. He served as Councillor on the MRS Executive Committee in 1996 and 1997, and he was elected Vice President for 1998, automatically serving as President in 1999. In 1988, he co-organized a symposium on science and technology of refractory metals at the MRS Spring Meeting, and in 1998, he served as one of the meeting chairs for the MRS Spring Meeting. He is also a past chair of the
International Relations Subcommittee of the External Affairs Committee.

\section{Michael J. Aziz \\ Councillor}

Michael J. Aziz, Gordon McKay Professor of Materials Science at Harvard University, focuses his research on the experimental and theoretical development of the understanding of the physical underpinnings of materials processing. His current interests are in the effects of stress on atomic transport kinetics; the phenomenological and the mechanistic modeling of the kinetics of diffusion, solidification, and thin-film growth; and experimental tests of such models. Aziz received his BS degree from the California Institute of Technology in 1978 and his PhD degree from Harvard in 1983, both in applied physics. He spent two years at Oak Ridge National Laboratory as a Eugene P. Wigner Postdoctoral Fellow before joining the faculty at Harvard. Among his awards are the IBM Faculty Development Award and the ONR Young Investigator Award, and he is a Fellow of the American Physical Society.

Aziz received an MRS Graduate Student Award and has served MRS as symposium organizer, co-chair of the 1995 Fall Meeting, principal editor of the Journal of Materials Research, and on several committees including the Awards Committee and the Program Committee. He served on the MRS Council since 1998.

\section{Alexander H. King Councillor}

Alexander H. King is head of the School and professor of Materials Engineering at Purdue University. He was previously a professor in the Department of Materials Science and Engineering at the State University of New York at Stony Brook where he had also served as vice provost for graduate studies. His research program focuses on interfacial structure and behavior, with extended interests in other areas including thin films, semiconductors, polymers, and materials processing. King received his BMet degree from the University of Sheffield and his doctorate degree, in 1979, from Oxford University. Following a brief period as a research fellow at Oxford, King joined the Massachusetts Institute of Technology as a postdoctoral associate. He joined the SUNY faculty in 1981 and left for Purdue in 1999.

At MRS, King has served on the Program Committee and its Meetings Quality Subcommittee. He was a symposium organizer at the 1993 MRS Fall Meeting and cochair of the 1997 MRS Spring Meeting where he implemented the Meeting Chairs' Poster Prize. He has served on the MRS Council since 1998. 